7. Pillai SK, Sakoulas G, Wennersten C, Eliopoulos GM, Moellering RC Jr, Ferraro $\mathrm{MJ}$, et al. Linezolid resistance in Staphylococcus aureus: characterization and stability of resistant phenotype. J Infect Dis. 2002;186:1603-7. DOI: 10.1086/345368

8. Mendes RE, Deshpande LM, Castanheira M, DiPersio J, Saubolle MA, Jones RN. First report of $c f r$-mediated resistance to linezolid in human staphylococcal clinical isolates recovered in the United States. Antimicrob Agents Chemother. 2008;52:2244-6. DOI: 10.1128/ AAC.00231-08

9. Farrell DJ, Morrissey I, Bakker S, Buckridge $\mathrm{S}$, Felmingham $\mathrm{D}$. In vitro activities of telithromycin, linezolid, and quinupristin-dalfopristin against Streptococcus pneumoniae with macrolide resistance due to ribosomal mutations. Antimicrob Agents Chemother. 2004;48:3169-71. DOI: 10.1128/AAC.48.8.3169-3171.2004

10. Kelly S, Collins J, Maguire M, Gowing C, Flanagan M, Donnelly M, et al. An outbreak of colonization with linezolidresistant Staphylococcus epidermidis in an intensive therapy unit. J Antimicrob Chemother. 2008;61:901-7. DOI: $10.1093 / \mathrm{jac} / \mathrm{dkn} 043$

Address for correspondence: Efi Petinaki, Department of Microbiology, University of Thessalia, Medical School Mezourlo, Larissa, Greece; e-mail: petinaki@med.uth.gr

\section{Buruli Ulcer in Long-Term Traveler to Senegal}

To the Editor: Buruli ulcer (BU) is caused by infection of subcutaneous fat with the environmental pathogen Mycobacterium ulcerans. BU has been reported or suspected in more than 30 countries. It has never been reported in Senegal and Guinea-Bissau (1). We report a case of travel-associated $\mathrm{BU}$ in a French traveler to Senegal.

The patient was a 24-year-old Caucasian man who came to the University Hospital of Bordeaux, France, with a nonhealing lesion on the ante- rior left leg that had been present for $\approx 12$ weeks. The patient had traveled in Senegal to the border of Guinea-Bissau from September 2006 through August 2007. His trip had begun in Dakar and proceeded south to the districts of Kaolack, Toubacouta, and Casamance. The patient stayed in Casamance during the rainy season from June 2007 through August 2007. He had been working on construction of wood dugouts, had been bare-legged regularly, and had been in contact with stagnant water.

He first noticed a lesion during June 2007, which had gradually increased to a small, centrally crusted ulcer. By the end of August 2007 (week 8 of the lesion), skin examination showed a $3 \times 6-\mathrm{cm}$ necrotizing ulcer with central crusting and an erythematous border (Figure). The lesion was not warm or tender but generated a seropurulent discharge. Concurrently, palpable left inguinal lymph nodes were observed.

Bacteriologic swabs identified Staphylococcus aureus and group A Streptoccocus pyogenes. Two punchbiopsy specimens were taken from the border of the lesion. Histologic analysis showed nonspecific acute and chronic dermal inflammation with necrotizing granulomas that ex-

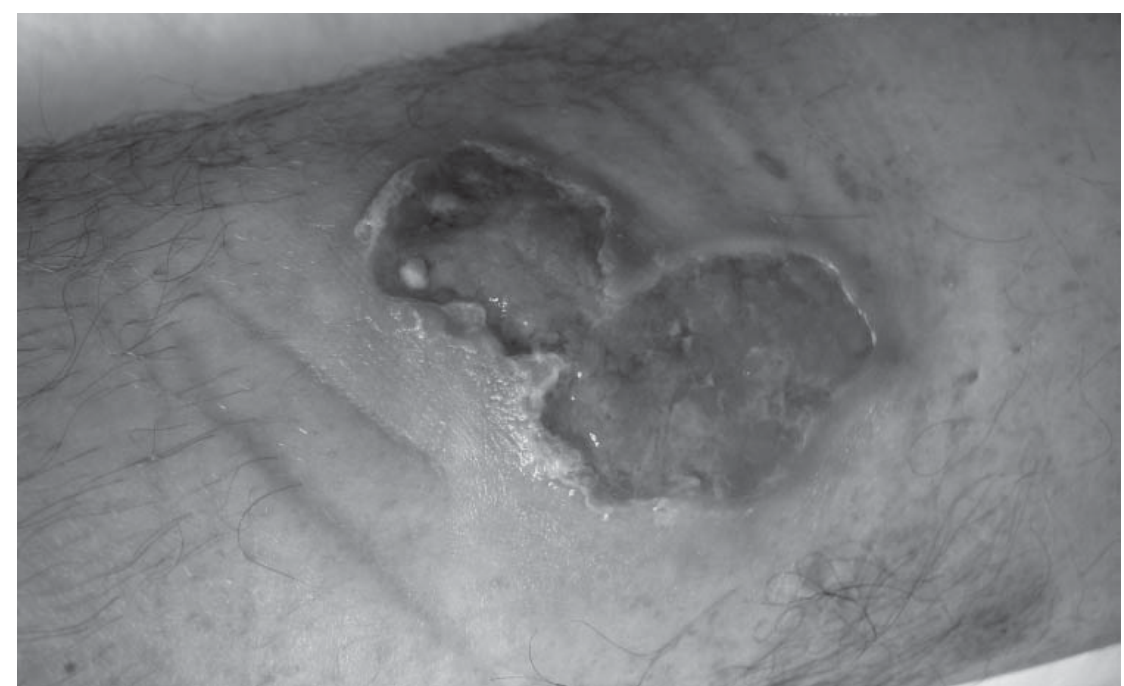

Figure. Ulcer $(3 \times 6 \mathrm{~cm})$ on anterior side of the left leg of the patient, showing an erythematous border. tended into the subcutaneous tissues, suggestive of infection with atypical Mycobacterium spp. Bacteriologic examination did not identify acid-fast bacilli (negative direct smear result after Ziehl-Neelsen staining) or other specific microorganisms (negative direct smear results after periodic acidSchiff, Giemsa, and Gram staining). Tissue specimens were placed into BACTEC 12B broth (Becton Dickinson, Franklin Lakes, NJ, USA) (incubated at $35^{\circ} \mathrm{C}$ ) and onto LöwensteinJensen slants (incubated at $30^{\circ} \mathrm{C}$ ). No growth was detected after 42 days. On the basis of clinical findings, we suspected a diagnosis of BU.

Taq-Man real-time quantitative PCR that used primers for $2 M$. ulcerans-specific genes (insertion sequence 2404 and ketoreductase B gene) $(2,3)$ and negative controls showed positive results for DNA from both biopsy specimens. A normalized standard curve was constructed, which indicated a bacterial load of $\approx 6 \times 10^{3}$ organisms/g of tissue.

Laboratory investigations indicated a total leukocyte count of 16,400 cells $/ \mu \mathrm{L}$ (reference range 3,60010,000 cells $/ \mu \mathrm{L}$ ) and a C-reactive protein level of $0.59 \mathrm{mg} / \mathrm{mL}$ (reference value $<0.01 \mathrm{mg} / \mathrm{mL}$ ). Results of radiologic investigations were normal. The 
patient was treated with rifampin $(600$ $\mathrm{mg}$ /day) and moxifloxacin (400 mg/ day) for 12 weeks. Additional surgical excision was planned 4 weeks after treatment was begun. Unfortunately, 15 days later, the patient was lost to follow-up.

$\mathrm{BU}$ has been reported in many West African countries, with Guinea being the northern limit of reported cases. Detection of this case of BU suggests that the region in West Africa endemic for this disease has been underestimated or is expanding. Infection in the traveler may have occurred in Casamance, if one assumes an incubation period of 6 weeks to 3 months. Further cases should be actively sought in this region and adjoining districts visited to evaluate the geographic extent of the disease.

The environmental reservoir and mode of transmission of BU in our patient are unknown. Exposure of unprotected skin with stagnant or slowflowing water is linked with BU. Our patient reported prolonged contact with water during his occupation. Recent studies implicating aquatic predator insects $(4,5)$ and mosquitoes $(6)$ in transmission of BU suggest that use of insect repellents and protective clothing may help prevent infection.

The diagnosis of BU in this patient relied on the PCR detection of 2 $M$. ulcerans-specific genes; this procedure is considered adequate $(7,8)$. The relatively low number of organisms detected may explain the negative acid-fast bacilli smear and culture results (9). Our report of $M$. ulcerans infection from Senegal is not surprising because southern Senegal shares similar ecologic features with neighboring affected countries, especially during the heavy rainy season.

Although BU is a disease that affects mainly persons in recognized disease-endemic areas, this case emphasizes that tropical skin ulcers should be considered in differential diagnosis of BU in travelers returning from disease-endemic countries $(1,10)$.
Diagnostic delays can be avoided by use of $M$. ulcerans-specific PCR, a test available from World Health Organization collaborating laboratories, which enables rapid confirmation of diagnosis of BU.

This study was supported by the Fondation Raoul Follereau, the European Community, and the Institut National de la Santé et de la Recherche Médicale, France.

\section{Khaled Ezzedine, ${ }^{1}$ Thierry Pistone, ${ }^{1}$ Jane Cottin, Laurent Marsollier, Véronique Guir, and Denis Malvy}

Author affiliations: Centre Hospitalier Université St-André, Bordeaux, France (T. Pistone, K. Ezzedine, D. Malvy); Centre Hospitalier Université Angers, Angers, France (J. Cottin, L. Marsollier); and Centre Hospitalier Saint-Nazaire, Saint-Nazaire, France (V. Guir)

\section{DOI: 10.3201/eid1501.080123}

\section{References}

1. World Health Organization. Buruli ulcer disease. Mycobacterium ulcerans infection: an overview of reported cases globally. Wkly Epidemiol Rec. 2004;79:194200.

2. Fyfe JA, Lavender CJ, Johnson PD, Globan M, Sievers A, Azuolas J, et al. Development and application of two multiplex real-time PCR assays for the detection of Mycobacterium ulcerans in clinical and environmental samples. Appl Environ Microbiol. 2007;73:4733-40. DOI: 10.1128/AEM.02971-06

3. Rondini S, Mensah-Quainoo E, Troll H, Bodmer T, Pluschke G. Development and application of real-time PCR assay for quantification of Mycobacterium ulcerans DNA. J Clin Microbiol. 2003;41:4231-7. DOI: 10.1128/JCM.41.9.4231-4237.2003

4. Marsollier L, Robert R, Aubry J, Saint André JP, Kouakou H, Legras $\mathrm{P}$, et al. Aquatic insects as a vector for Mycobacterium ulcerans. Appl Environ Microbiol. 2002;68:4623-8. DOI: 10.1128/ AEM.68.9.4623-4628.2002

${ }^{1}$ These authors contributed equally to this article.
5. Portaels F, Meyers WM, Ablordey A, Castro AG, Chemlal K, de Rijk P, et al. First cultivation and characterization of Myсоbacterium ulcerans from the environment. PLoS Negl Trop Dis. 2008;2:e178. DOI: 10.1371/journal.pntd.0000178

6. Johnson PD, Azuolas J, Lavender CJ, Wishart E, Stinear TP, Hayman JA, et al. Mycobacterium ulcerans in mosquitoes captured during outbreak of Buruli ulcer, southeastern Australia. Emerg Infect Dis. 2007;13:1653-60.

7. Buruli ulcer: progress report, 2004-2008. Wkly Epidemiol Rec. 2008;83:145-54.

8. Johnson PD, Hayman JA, Quek TY, Fyfe JA, Jenkin GA, Buntine JA, et al. Mycobacterium ulcerans Study Team. Consensus recommendations for the diagnosis, treatment and control of Mycobacterium ulcerans infection (Bairnsdale or Buruli ulcer) in Victoria, Australia. Med J Aust. 2007;186:64-8.

9. Marsollier L, Prévot G, Honoré N, Legras P, Manceau AL, Payan C, et al. Susceptibility of Mycobacterium ulcerans to a combination of amikacin/rifampicin. Int $\mathbf{J}$ Antimicrob Agents. 2003;22:562-6. DOI: 10.1016/S0924-8579(03)00240-1

10. Semret M, Koromihis G, MacLean JD, Libman M, Ward B. Mycobacterium ulcerans infection (Buruli ulcer): first reported case in a traveler. Am J Trop Med Hyg. 1999;61:689-93.

Address for correspondence: Khaled Ezzedine, Unité de Médecine Tropicale et Pathologie d'Importation, Service de Médecine Interne et des Maladies Tropicales, Hôpital Saint-AndréCentre Hospitalier Université Bordeaux, 1, Rue Jean Burguet, F-33 075 Bordeaux CEDEX, France; email: khaled.ezzedine@ chu-bordeaux.fr

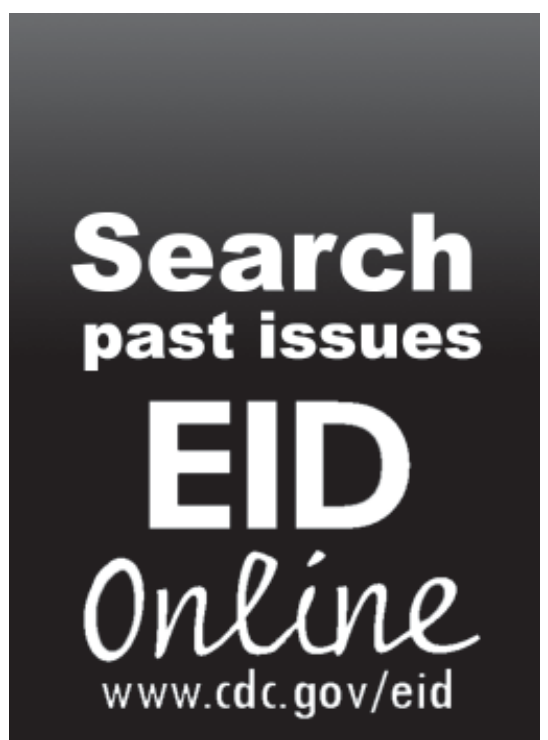

